\title{
Establishing stable sinus rhythm in an endurance athlete with paroxysmal supraventricular tachycardia improves haemodynamical performance during exercise testing
}

\author{
Paul Zimmermann, ${ }^{1}$ Christoph Lutter ${ }^{2}$
}

${ }^{1}$ Cardiology, Sozialstiftung Bamberg, Bamberg, Bayern, Germany

${ }^{2}$ Department of Orthopedics, University Medical Center Rostock, Rostock, Germany

\section{Correspondence to}

PD Dr. med. Christoph Lutter christoph.lutter@googlemail. com

Accepted 25 August 2020
Check for updates

(C) BMJ Publishing Group Limited 2020. No commercial re-use. See rights and permissions. Published by BMJ.

To cite: Zimmermann $\mathrm{P}$, Lutter C. BMJ Case Rep 2020:13:e238674. doi:10.1136/bcr-2020 238674

\section{DESCRIPTION}

Atrial fibrillation is a commonly known heart rhythm abnormality that occurs not only in the general population but also in endurance athletes. Various studies have even described an increased prevalence among athletes. ${ }^{1-4}$

We recently presented the case of a wellexperienced 60-year-old man endurance Ironmantriathlon athlete $(187 \mathrm{~cm}, 92 \mathrm{~kg}$, average training level: 10-15 hours/week) who had presented with intermittent shortness of breath and heart palpitations during his training sessions in his daily routine. ${ }^{5}$ His medical history showed an isthmus ablation caused by typical atrial flutter and a clinically stable arterial hypertension. The echocardiographic data showed a normal size of the left ventricle (left ventricular end diastolic diameter (LVedd) $42 \mathrm{~mm}$ ), no hypertrophia of the left ventricular walls (interventricular septum thickness (IVSd) $11 \mathrm{~mm}$, posterior wall thickness in systole (PWTs) $11 \mathrm{~mm}$ ), a minimal enlargement of the left atrium (LA $21 \mathrm{qcm}$ ) and a normal ejection fraction (55\%). Cardiopulmonary exercise testing (CPEX, ergometer bike) revealed an episode of paroxysmal supraventricular tachycardia (SVT, maximum effort $250 \mathrm{~W}$ ). We were able to graphically record the degree to which the athlete's performance was reduced (figures 1 and 2). The patient's oxygen pulse decreased pathologically and his $\mathrm{VO}_{2}$ oxygen uptake during the SVT was limited (figures 1 and 2).

In the course of a recently conducted further examination and therapy of the same patient, we performed an electrophysiological examination with an ablation of the pulmonary veins (pulmonary vein isolation with a three-dimensional mapping system) and re-evaluated the patient's clinical performance with a further echocardiographic examination and a CPEX on an ergometer bike. The echocardiographic data showed a stable trend in the follow-up appointment (LVedd $43 \mathrm{~mm}$, IVSd $11 \mathrm{~mm}$, PWTs $11 \mathrm{~mm}$, LA $20 \mathrm{qcm}$, normal ejection fraction 55\%-60\%). After the CPEX testing, the patient recovered fast and no episodes of SVT were detected. The haemodynamic influence of the established stable sinus rhythm was recorded graphically in the comparison of pre-interventional and postinterventional CPEX figures (figures 1 and 2 vs figures 3 and 4).

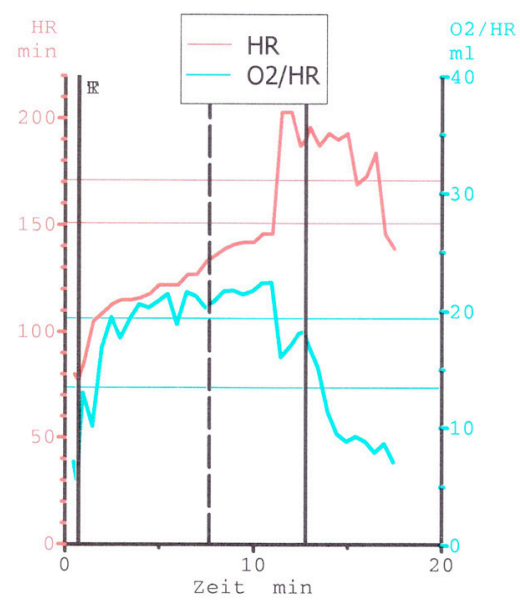

Figure 1 Impairment of the oxygen pulse during the cardiopulmonary exercise caused by atrial fibrillation (starting within minute 11) and showing the gap between the tachycardia (red colour) and oxygen pulse (blue colour).

Our case graphically shows the haemodynamic influence of a paroxysmal atrial fibrillation and the consequent reduced performance of a patient during CPEX. According to the clinical appearance and the athlete's reporting, it highlights the

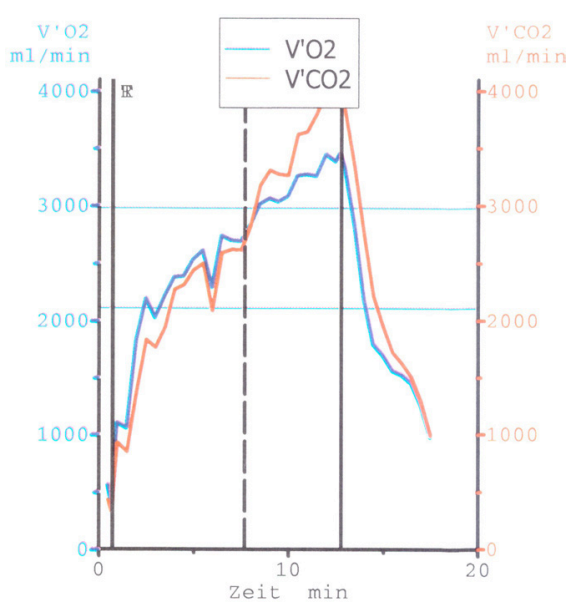

Figure 2 Graphical record of the athlete's impairment referring his $\mathrm{VO}_{2}$ max uptake caused by atrial fibrillation, missing the typical levelling off phenomenon by endurance athletes at the end of the cardiopulmonary exercise testing. 


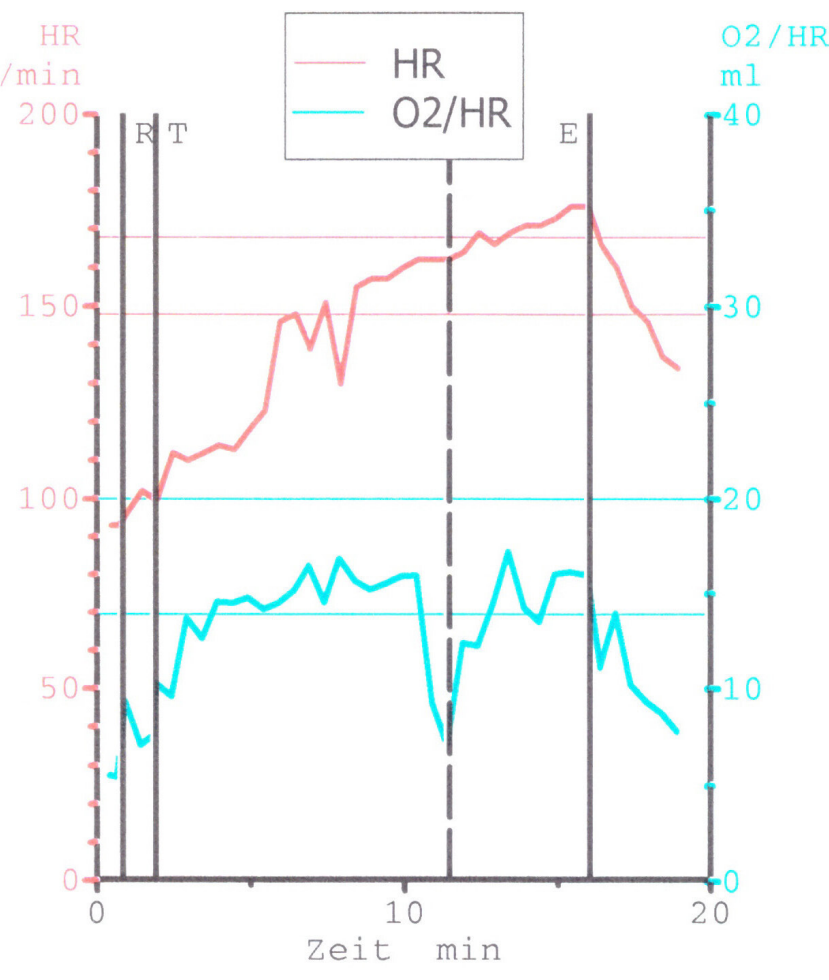

Figure 3 Process of the oxygen pulse during cardiopulmonary exercise with stable sinus rhythm in comparison to figure 1 without the gap between heart rate (red colour) and oxygen pulse (blue colour).

impact of a stable sinus rhythm on the performance of endurance athletes. $^{23}$

In this context, we recently presented our first findings before establishing a stable sinus rhythm. ${ }^{5}$ By mapping the LA during the electrophysiological examination with an ablation of the pulmonary veins (pulmonary vein isolation with a three-dimensional mapping system), signs of atrial myocardial fibrosis could be

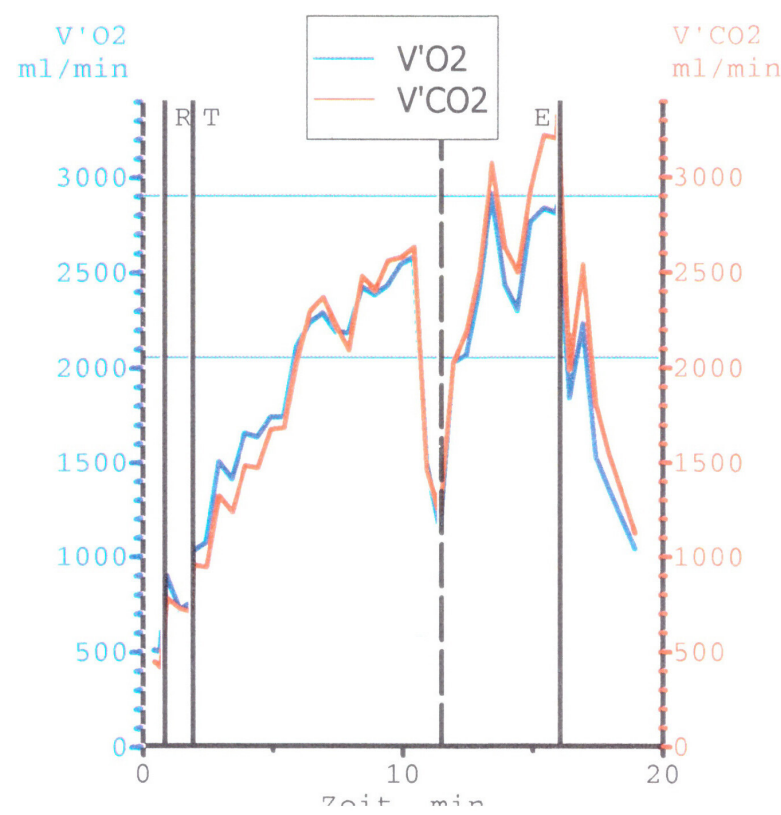

Figure 4 Graphical record of the athlete's VO, max uptake without the impairment in figure 2 and the typical levelling off phenomenon by endurance athletes at the end of the cardiopulmonary exercise testing.

\section{Learning points}

- The presented follow-up investigation of our previously published case graphically shows the haemodynamic effect of recovery of a stable sinus rhythm after prior paroxysmal supraventricular tachycardia on the athlete's performance during a cardiopulmonary exercise test.

- Although different pathological mechanisms for underlying etiological reasons are discussed, maximum efforts should be focused on establishing a stable sinus rhythm in endurance athletes in order to improve their cardiac function and exercise capacity.

- Therapeutic approaches should be individually tailored according to the athletes' demands.

detected in our athlete. This is one of the various aspects of this condition, which are widely discussed, presupposing the relation between high endurance training and the prevalence of atrial fibrillation. ${ }^{1-4}$ Causes for the higher prevalence of atrial fibrillation include: (1) myocardial fibrosis, which is sometimes caused by the accumulation of lifelong training hours and increased atrial filling pressure, ${ }^{4}(2)$ varying amplitude of the autonomic nervous system, (3) increased baroreflective responsiveness and (4) increased sensitivity of cardiomyocytes to cholinergic stimulation. $^{16}$

The development of atrial fibrillation in endurance athletes with prior ablation of atrial flutter is a commonly known occurrence. ${ }^{6}$ The recently reported 'paroxysmal AF in young and middle-aged athletesA' (PAFIYAMA) syndrome is also an interesting fact in this context; our athlete might fulfil these criteria. ${ }^{78}$

In summary, the presented case shows the importance of establishing a stable sinus rhythm in endurance athletes to improve their haemodynamical performance in CPEX. As mentioned above, these facts have been graphically proved and our findings emphasised the importance of an individualised patient's treatment strategy in PAFIYAMA syndrome. Therefore, a sustained cardiac functional improvement after establishing a stable sinus rhythm suggests an improvement of quality of life and an objective improvement of cardiac function and exercise capacity in these athletes/patients. ${ }^{9-11}$

Contributors $\mathrm{PZ}$ and $\mathrm{CL}$ designed data collection tools, monitored data collection for the Case Report, cleaned and analysed the data and drafted and revised the paper. Both authors have read and approved the final version of the manuscript.

Funding The authors have not declared a specific grant for this research from any funding agency in the public, commercial or not-for-profit sectors.

Competing interests None declared.

Patient consent for publication Obtained.

Provenance and peer review Not commissioned; externally peer reviewed.

\section{REFERENCES}

1 Müssigbrodt A, Richter S, Hindricks G, et al. Vorhofflimmern bei Ausdauersportlern (atrial fibrillation in endurance athletes); Deutsche Zeitschrift für Sportmedizin, Jahrgang 61, NR. 9, 2010.

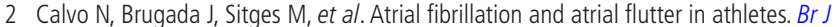
Sports Med 2012;46 Suppl 1:i37-43.

3 Hoogsteen J, Schep G, Van Hemel NM, et al. Paroxysmal atrial fibrillation in male endurance athletes. A 9-year follow up. Europace 2004;6:222-8.

4 Wilhelm M. Atrial fibrillation in endurance athletes. Eur J Prev Cardiol 2014;21:1040-8

5 Zimmermann P, Lutter C. Haemodynamic effects of paroxysmal supraventricular tachycardia in an endurance athlete during exercise testing. BMJ Case Rep 2019;12:e231659. 
6 Heidbüchel H, Anné W, Willems R, et al. Endurance sports is a risk factor for atrial fibrillation after ablation for atrial flutter. Int J Cardiol 2006;107:67-72.

7 Sanchis-Gomar F, Perez-Quilis C, Lippi G, et al. Atrial fibrillation in highly trained endurance athletes - Description of a syndrome. Int J Cardiol 2017;226:11-20.

8 Fragakis N, Vicedomini G, Pappone C, et al. Endurance sport activity and risk of atrial fibrillation - epidemiology, proposed mechanisms and management. Arrhythm Electrophysiol Rev 2014;3:15-19.
9 Gilbert KA, Hogarth AJ, MacDonald W, et al. Restoration of sinus rhythm results in early and late improvements in the functional reserve of the heart following direct current cardioversion of persistent AF: FRESH-AF. Int J Cardiol 2015;199:121-5.

10 Wozakowska-Kapłon B, Opolski G. Effects of sinus rhythm restoration in patients with persistent atrial fibrillation: a clinical, echocardiographic and hormonal study. Int $\lrcorner$ Cardiol 2004:96:171-6.

11 Wozakowska-Kapłon B, Opolski G. Improvement in exercise performance after successful cardioversion in patients with persistent atrial fibrillation and symptoms of heart failure. Kardiol Pol 2003;59:213-23.

Copyright 2020 BMJ Publishing Group. All rights reserved. For permission to reuse any of this content visit

https://www.bmj.com/company/products-services/rights-and-licensing/permissions/

BMJ Case Report Fellows may re-use this article for personal use and teaching without any further permission.

Become a Fellow of BMJ Case Reports today and you can:

- Submit as many cases as you like

- Enjoy fast sympathetic peer review and rapid publication of accepted articles

Access all the published articles

Re-use any of the published material for personal use and teaching without further permission

\section{Customer Service}

If you have any further queries about your subscription, please contact our customer services team on +44 (0) 2071111105 or via email at support@bmj.com.

Visit casereports.bmj.com for more articles like this and to become a Fellow 